\title{
Analysis of the causes of destruction of gas pipelines
}

\author{
Natalya Volgina ${ }^{1, *}$, Aleksander Shulgin ${ }^{1}$, Svetlana Khlamkova ${ }^{1}$, Guzel Sharipzyanova ${ }^{1}$, and \\ Yakov Vorobyov ${ }^{2}$ \\ ${ }^{1}$ The Moscow polytechnical university, B. Semenovskaya St., 38, Moscow, 107023, Russia \\ ${ }^{2}$ ROSEN Group Location Lingen (Ems) Am Seitenkanal 8 49811, Germany
}

\begin{abstract}
The analysis of causes of destruction of main gas pipelines for the last two decades is carried out. It is shown that the share of accidents because of corrosion cracking energized increases. The conclusion is drawn that inspection and repair of emergency sites has to become a paramount task. It will allow to reach considerable decrease in accident rate. At the same time the extent of emergency sites of gas pipelines with a diameter of $1420 \mathrm{~mm}$ is about $1700 \mathrm{~km}, 1220 \mathrm{~mm}-1000 \mathrm{~km} ; 1020 \mathrm{~mm}-400 \mathrm{~km}$ that, generally, makes $2.3 \%$ of the total extent of gas pipelines of the corresponding diameters $(1020-1420 \mathrm{~mm})$.
\end{abstract}

Analysis of accident statistics of gas pipelines [1 - 4] shows that accident rate of gas pipelines stabilized or decreased for all reasons except corrosion cracking of pipes under stress (SCC or stress corrosion). The number of accidents of gas pipelines due to stress corrosion cracking is increasing.

Prior to 1990, the number of accidents of Russian gas pipelines due to SCC and associated gas losses did not exceed $10 \%$ of all accidents [1]. Then, the accident rate of gas pipelines due to SCC began to increase sharply and over the period 1996-2017, the number of these accidents amounted to $38 \%$ of the total number of accidents.

The main conclusion, led by many years of research of pipes destroyed in case of accidents, is that areas of pipe sheet with abnormally high density of non-metallic inclusions are preferred places of occurrence of defects of any kind [4].

Therefore, when producing pipe steels, special attention should be paid to cleaning steel and modifying non-metallic inclusions. Treatment with silicocalcium and rare earth metals contributes to the globularization of sulfide non-metallic inclusions and increases tear resistance

With the increase in the life of gas pipelines, the number of defects growing to critical sizes is steadily increasing. If these defects are not rectified in a timely manner, there will inevitably be an increase in accident rate due to SCC.

Fig. 1 shows the dependence of the number of accidents attributed to the length of gas pipelines on time.

\footnotetext{
${ }^{*}$ Corresponding author. nvolgina2008@gmail.com
} 


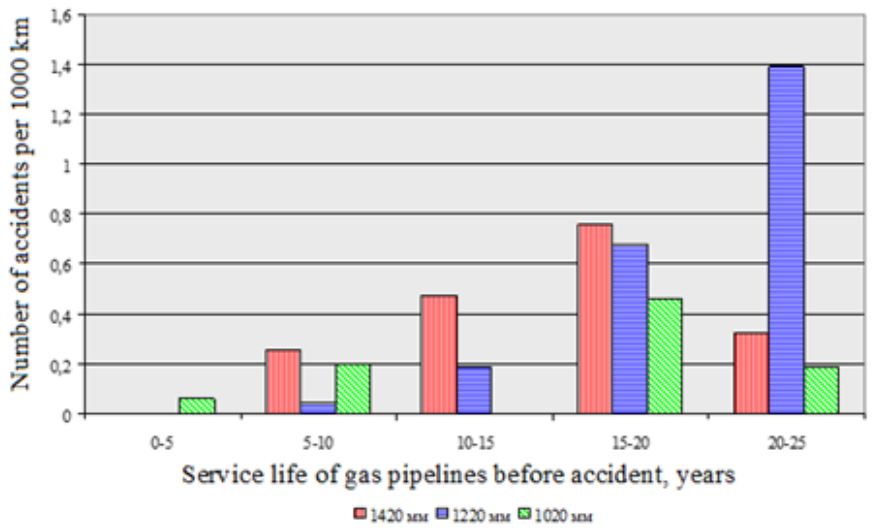

Fig. 1. The dependence of the number of accidents per $1000 \mathrm{~km}$ of gas pipelines on the duration of their operation.

As can be seen from Fig. 1, the accident rate of gas pipelines increases significantly with the increase in their service life. The lower value of the relative number of accidents of gas pipelines with a diameter of $1420 \mathrm{~mm}$ in the interval of $20-25$ years is due to the fact that most of the gas pipelines built using film insulation have not yet reached the 20-year service life, and measures implemented in the last 10 years by Gazprom to prevent accidents (in-tube flaw detection, inspection in long pits and overhaul) $[5,6]$. The lower value of the relative number of accidents of gas pipelines with a diameter of $1020 \mathrm{~mm}$ in the interval of 20-25 years is associated with the replacement of a large number of French-made pipes made from low-quality steel of a controlled roller in emergency sections of gas pipelines and heatstrengthened pipes manufactured by the Volzhskiy pipe plant in emergency sections of the gas pipeline before their 20-year life [7-9].

The nature of the distribution of accidents in the gas pipeline system of Gazprom is significantly influenced by the technology for the production of pipes from which gas pipelines are made. Fig. 2 shows the distribution of accidents of gas pipelines of various diameters, made of different steels (controlled rolling, normalized and thermally strengthened), according to the time to the accident and the distance from the combustion chamber.

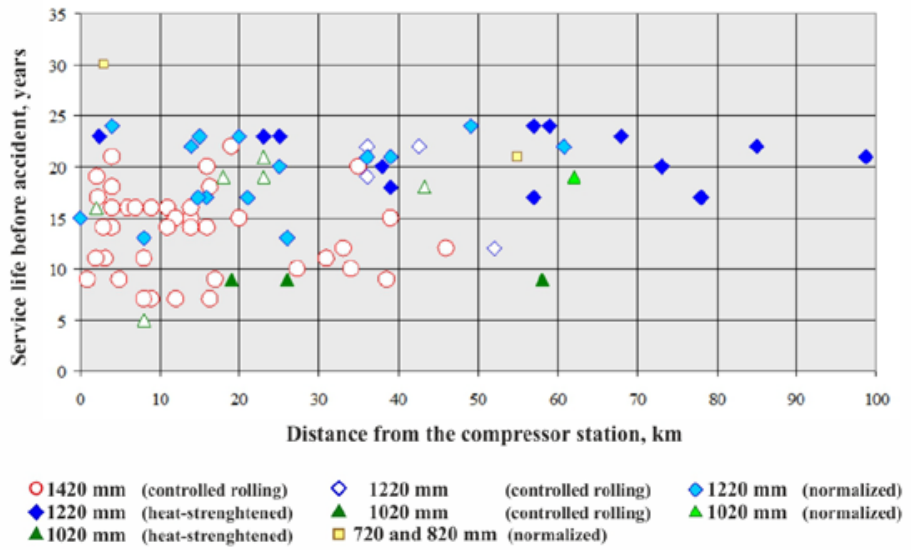

Fig. 2. Distribution of accidents of gas pipelines of different diameters, made of different steels (controlled rolling, normalized and heat-strengthened), according to the time before the accident and the distance from the compressor station. 
Fig. 3 shows histograms of distribution of emergency breakages of pipes made of different steels depending on distance from combustion chamber.

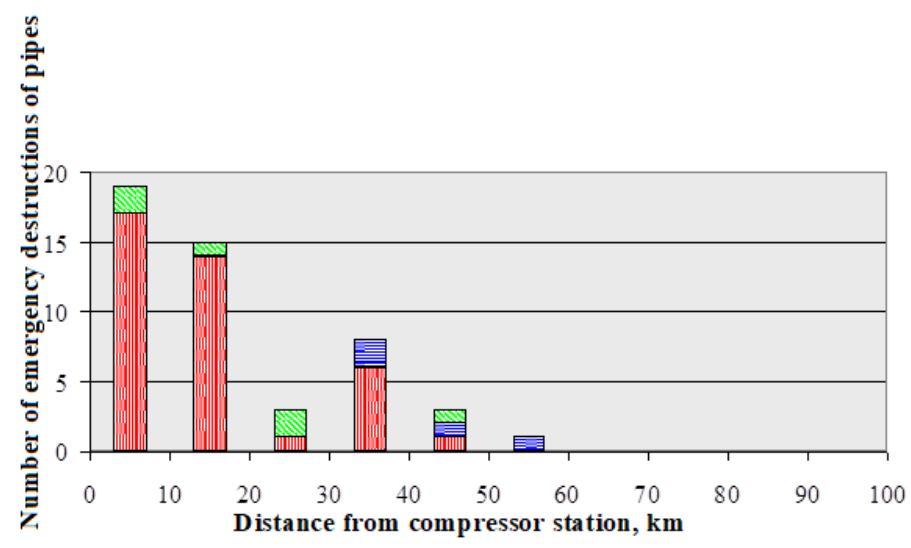

a

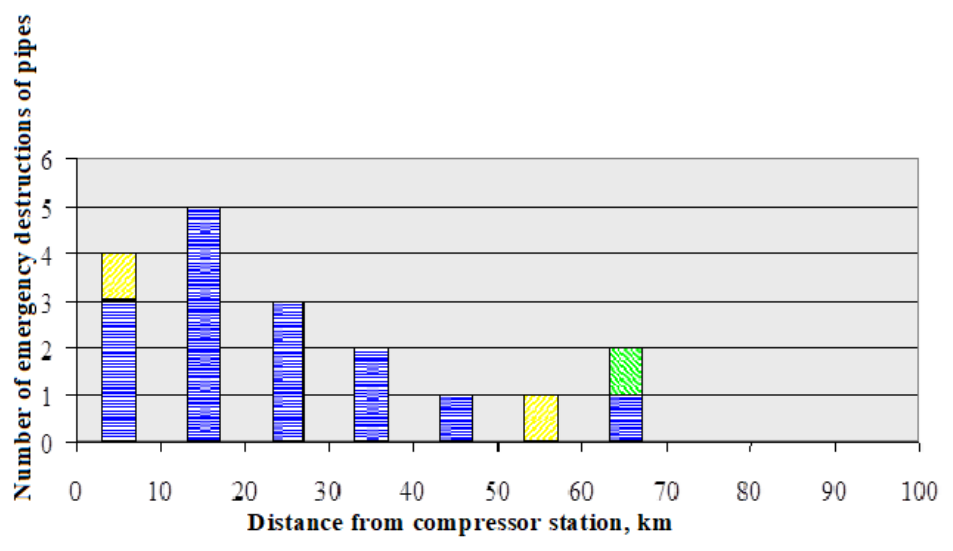

b

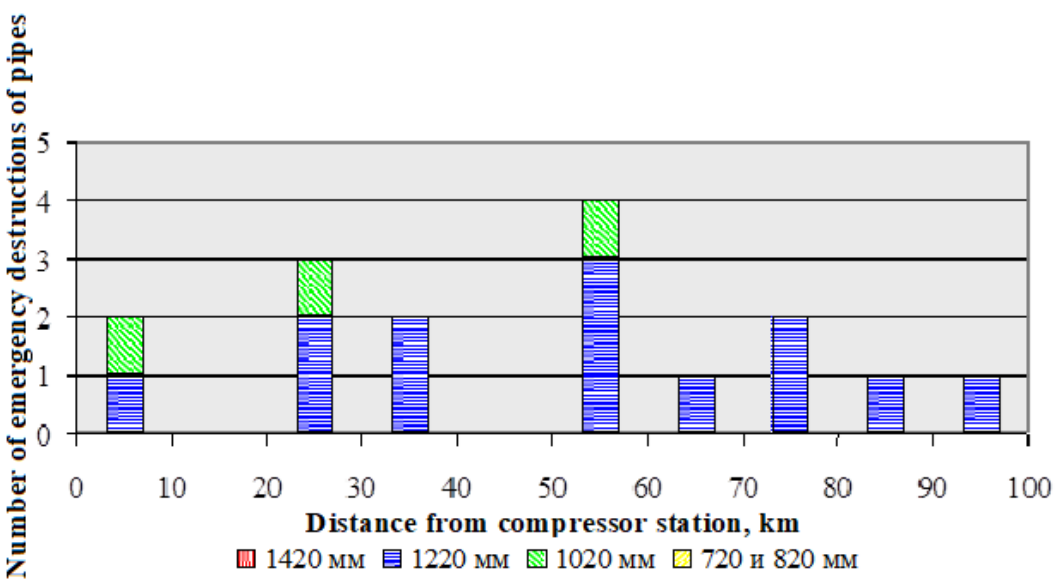

C

Fig. 3. The dependence of the number of emergency pipe failures on the distance from the compressor station: a - pipes from steels of controlled rolling; b - pipes from normalized steels; $\mathrm{c}$ pipes thermally strengthened. 
The dependence of the number of emergency damages on the distance from the combustion chamber is observed only for pipes with a diameter of $1420 \mathrm{~mm}$, made of steels of controlled rolled stock, as well as pipes with a diameter of $1220 \mathrm{~mm}$, made of normalized steel (Fig. 3). This means that for these pipes, the number of stress corrosion defects that have arisen and are developing depends on stresses in the pipe walls. Such dependence was probably related to pipe technology $[6,7]$.

Stress-corrosion defects are born in the zones of predisposition of pipes to SCC, in which stress concentrators were formed - longitudinally oriented surface defects, cracks in the surface layer on the edges of sheets, process strips, anomalies along the welding line with the base metal. Studies carried out during the inspection of gas pipelines, the investigation of their failures and in the technological flow of pipe production at pipe plants indicate that the predisposition of pipes to SCC is due to the process of their production and depends on the applied technology for the manufacture of sheets and pipes, in particular, molding and welding [8 -10].

Obviously, in order for SCC to develop in the zone of the pipe's predisposition to cracking, a tensile stress sufficient for the onset and growth of stress-corrosion cracks must act. The magnitude of this stress depends on the gas pressure in the pipe, its wall thickness, the value of the stress concentrator and the level of residual stress. The critical value of the stress concentrator corresponds to a certain level of stress in the pipe. In pipes there are stress concentrators of various sizes, while with an increase in the size of concentrators their number decreases sharply (the number of small concentrators significantly exceeds the number of large ones). Thus, the number of concentrators that can initiate the development of stress-corrosive de-facts for the above types of pipes is drastically reduced when the pressure in the pipe is reduced (increased distance from the compressor station) or its wall thickness increases.

The time to emergency destruction of pipes does not depend on the distance from the compressor station. From this it follows that the growth rate of stress-corrosion defects does not hang due to stresses in the walls of pipes.

When contact between the pipe and the electrolyte occurs, the process of accumulation of micro-damage on the metal surface begins. The mechanism of accumulation of microdamages may be different, but in gas pipelines, as a rule, the electrochemical process prevails, as a result of which the metal of the surface layer of the pipe, interacting with the medium, passes into chemically passive compounds (for example, siderite). These compounds form a film on the surface of the metal, which prevents the further process of accumulation of microwaves. If the process of accumulation of microwaves takes place at the top of the stress concentrator, at a certain level of the latter, it is possible to destroy the over-bearing layer (attenuated by microwaves of the metal with a passivation film) and form an unprotected metal surface.

On the resulting surface, the microperformation accumulation process would resume, after which the weakened surface layer would be destroyed and thus further growth of the generated stress-corrosion crack would occur. The dependence of the growth rate of stress corrosion defects on stresses indicates that this rate is determined by the rate of accumulation of micro-damage, i.e., depends on the environment and the properties of the pipe metal.

\section{Conclusion}

An analysis of the accident rate of gas pipelines shows that in recent years the main cause of destruction is SCC. At the same time, the share of accidents for this reason is constantly increasing. The vast majority of accidents (85\%) occurred in areas within which 2 or more accidents were recorded. From this it follows that first of all it is necessary to inspect and repair emergency areas, which will achieve a significant reduction in emergency conditions. 
Approximate length of emergency sections of gas pipelines with a diameter of $1420 \mathrm{~mm}$ is $1700 \mathrm{~km}, 1220 \mathrm{~mm}-1000 \mathrm{~km} ; 1020 \mathrm{~mm}-400 \mathrm{~km}$, which, in general, is $2.3 \%$ of the total length of gas pipelines of the corresponding diameters (1020-1420 mm).

\section{References}

1. R.N. Parkins, W.K. Blanchard, B.S. Delanty, Corrosion. v. 50 (5), pp. 394-408 (1994)

2. A.Yakovlev, S. Alennikov., S. Romantsov, Gas industry, May, pp. 63-64, (2003)

3. V. Remisov, F. Tukhbatullin, M. Korolev, Gas industry. Series: Rep. of pipel. Scien. and tech. coll.,pp.3-12, (2001)

4. A. Bykova, I. Veliyulin, A. Reshetnikov, N. Volgina. Met. Techn. 2. pp. $14-18$, (2015)

5. A. Kolotovsky, B. Rainov, M. Korolev, N. Volgina, Eleventh Intern. Busin. Meet. "Diagnostics 2001." v. 2, Part 2, pp.122-130, (2001)

6. S. Karpov, D. Shiryapov, A. Alihashkin, News of Gas Science, 3 (27), pp. 143-153, (2016)

7. A.B. Dokutovich, S.V. Kovalenko, A.N. Kuznetsov, Y.V. Nemchin, V.D. Mess. of Gas Sc., 3 (27), pp. 54-78, (2016)

8. I. Rodionova, A. Zaitsev, O. Baklanova, A. Kazankov, Metall. v. 59, 9, pp. 774-783, (2016)

9. S. Guskov,V. Musonov, R. Aginya,Pipt. Pipeline transport: theory and practice, pp. 3034, (2016)

10. A. Mitrofanov, M. Petrova, I. Kirillov, I. Rodionova, K. Hoopoe, Metall., 1, pp. 71-74 